\title{
Prevalence of Anxiety May Not be Elevated in Thai Ovarian Cancer Patients Following Treatment
}

\author{
Saranya Chittrakul ${ }^{1}$, Kittipat Charoenkwan ${ }^{1 *}$, Nahathai Wongpakaran ${ }^{1}$
}

\begin{abstract}
Background: To compare prevalence of anxiety in ovarian cancer patients following primary treatment to that of normal women and to examine predicting factor. Materials and Methods: In this cross-sectional study, 56 ovarian cancer patients who had primary surgical treatment within the past five years (cancer group) and 56 age-matched women who attended an outpatient clinic for check-ups (non-cancer group) were recruited from June 2013 to January 2014. The hospital anxiety and depression scale (HADS), was used to determine anxiety level of the participants with the score of $\geq 11$ suggestive of anxiety. The prevalence of anxiety symptoms and mean HADS scores for anxiety were compared between the study groups. For those with ovarian cancer, associations of demographic and clinical factors with anxiety was examined. A p-value of $<0.05$ was considered significant. Results: Participants in the non-cancer group had higher rate of medical comorbidity, higher salary, and more frequent university education. The prevalence of anxiety was not different between the groups, at $7.1 \%$ each. The mean HADS scores for anxiety subscale were not significantly different between the groups, 5.0 in the cancer group vs 6.1 in the non-cancer group $(\mathrm{p}=0.09)$. On multivariable analysis, no demographic or clinical factors significantly associated with anxiety were identified. For the cancer group, no association between any particular factors and anxiety was demonstrated. Conclusions: The prevalence of anxiety in women with ovarian cancer following primary treatment was comparable to that of normal women seeking routine check-up.
\end{abstract}

Keywords: Anxiety - HADS - hospital anxiety and depression scale - ovarian cancer

Asian Pac J Cancer Prev, 16 (3), 1251-1254

\section{Introduction}

Ovarian cancer is the leading cause of global gynecologic cancers death. Its incidence varies between different regions, highest in industrialized countries, and is closely associated with reproductive and socioeconomic status (Fleming et al., 2013). The disease is generally less common in Asia with age-standardized incidence rate (ASR) ranging from 2.3 per 100,000 person-years in Cixian County, China to 12.6 per 100,000 person-years in Manila, the Philippines. In Chiang Mai, Thailand, the ASR for ovarian cancer was 5.1 per 100,000 person-years during 2003-2007 (Forman et al., 2013) However, there was an increasing trend in the incidence rate of ovarian cancer in many registries (Murthy et al., 2009).

It is generally accepted that older age, high-stage, and high-grade are associated with poorer prognosis (Fleming et al., 2013). At the time of diagnosis, approximately $70 \%$ of patients with epithelial ovarian cancer had advanced (stage III or IV) diseases and $44 \%$ had grade 3 tumors (Chan et al., 2006). Modern management of ovarian cancer includes primary surgery to remove tumor bulks followed by four to six cycles of combination chemotherapy (Rai et al., 2014). Five-year survival rates for patients with epithelial ovarian cancer range from almost $90 \%$ in stage I, $35-45 \%$ in stage III, to around $20 \%$ in stage IV (Fleming et al., 2013). Following the diagnosis, there is high possibility of limited functional capacity, decreased sexual function, and compromised family and social role (Akkuzu 2012; Akkuzu and Ayhan, 2013; Akkuzu et al., 2014). As a consequence, one would expect an increase in prevalence of anxiety in women diagnosed with ovarian cancer (Reid et al., 2011; Clevenger et al., 2013). However, there has been no evidence to prove that this is the case.

The objectives of this study were to compare prevalence of anxiety symptoms in women with ovarian cancer following primary treatment to that of women attending the outpatient clinic for check-up and to examine predicting factors for anxiety in the women with ovarian cancer.

\section{Materials and Methods}

This cross-sectional analytical study was conducted at department of obstetrics and gynecology, faculty of medicine, Chiang Mai University from June 2013 to 
Saranya Chittrakul et al

August 2014. After Institutional Review Board approval, 56 consecutive patients with ovarian cancer of any stages and cell types, age 18-65 years old, who had primary surgical treatment within the past five years at our hospital (cancer group) and 56 age-matched women who attended our outpatient clinic during the same period for check-up (non-cancer group) were recruited. Exclusion criteria included not having primary surgical treatment and not being able to communicate in Thai. All patients gave their verbal and written informed consent prior to participation. Demographic and clinical data were collected. The self-administered questionnaire, hospital anxiety and depression scale (HADS; Thai version) (Nilchaikovit et al., 1996) (Zigmond and Snaith, 1983), was employed to determine anxiety and depression symptoms of the participants. Each patient was provided with the questionnaires and was asked to complete them independently by herself while waiting to see the doctors. It was composed of 14 items, seven for anxiety assessment and seven for depression assessment. Each item was a four-point Likert scale ranging from 0 (the least anxious/ depressed) to 3 (the most anxious/depressed). At the end of the assessment, the total scores for anxiety subscale (seven anxiety-related items; HADS-A) and depression subscale (seven depression-related items; HADS-D) were considered separately. For each subscale, the score of 8-10 was suggestive of borderline anxiety or depressive symptoms while the score of $\geq 11$ indicated clinical anxiety or depression (or significant anxiety or depression symptoms) (Nilchaikovit et al., 1996). Internal consistency of the subscales was examined by using the Cronbach's alpha statistics. The primary outcome of this study was anxiety symptoms based on the HADS-A score of $\geq 11$. Depression was the secondary outcome based on the HADS-D score of $\geq 11$. The prevalence of anxiety and depression and mean HADS scores for anxiety and depression were compared between the study groups employing chi-squared test or Fisher's exact test and student's t-test, respectively. Multivariable analysis using logistic regression was performed to examine the association between demographic/clinical factors including study group (cancer vs non-cancer), age, marital status, religion, alcohol consumption, co-morbidity, salary, and education and anxiety. For those with ovarian cancer, association of clinical and pathological factors with anxiety was examined. Subgroup analyses to compare HADS-A scores according to disease stage (early $v s$ advanced) and histology (epithelial vs non-epithelial) were performed. Statistical analysis was performed by using Stata ${ }^{\circledR}$ program version 12 (StataCorp LP, College Station, Texas, USA). The $\mathrm{p}$-value of $<0.05$ was considered significant.

\section{Results}

One hundred and twelve patients, 56 in cancer group and 56 in non-cancer group, participated in the study. Median age was 53 years (range 18-65 years), 51.5 years in the cancer group and 54.5 years in the non-cancer group. Demographic data for both groups are presented in Table 1. The two study groups were similar with respect to age, marital status, religion, smoking, and
Table 1. Demographic and Clinical Data

\begin{tabular}{|c|c|c|c|c|}
\hline Characteristics & $\mathrm{N}$ & $\begin{array}{l}\text { Cancer } \\
\mathrm{N}(\%)\end{array}$ & $\begin{array}{c}\text { Non-cancer } \\
\mathrm{N}(\%)\end{array}$ & $\overline{\text { P-value }}$ \\
\hline \multicolumn{5}{|l|}{ Age, years } \\
\hline$<50$ & 36 & 17 (30.4) & $19(33.9)$ & 0.69 \\
\hline$\geq 50$ & 76 & 39 (69.6) & $37(66.1)$ & \\
\hline \multicolumn{5}{|l|}{ Marital status } \\
\hline Non-married & 44 & $23(41.1)$ & $21 \quad(37.5)$ & 0.70 \\
\hline Married & 68 & $33(58.9)$ & $35(62.5)$ & \\
\hline \multicolumn{5}{|l|}{ Religion } \\
\hline Buddhist & 105 & $54(96.4)$ & 51 (91.1) & 0.44 \\
\hline Others & 7 & $2 \quad(3.6)$ & $5 \quad(8.9)$ & \\
\hline \multicolumn{5}{|l|}{ Smoking } \\
\hline Yes & - & - & - & - \\
\hline No & 112 & $56(100.0)$ & $56(100.0)$ & \\
\hline \multicolumn{5}{|l|}{ Alcohol } \\
\hline Yes & 7 & $1 \quad(1.8)$ & $6(10.7)$ & 0.11 \\
\hline No & 105 & 55 (98.2) & $50(89.3)$ & \\
\hline \multicolumn{5}{|l|}{ Comorbidity } \\
\hline Yes & 44 & $14(25.0)$ & $30(53.6)$ & $0.002 *$ \\
\hline No & 68 & $42(75.0)$ & $26(46.4)$ & \\
\hline \multicolumn{5}{|l|}{ Salary } \\
\hline$\leq 10,000$ & 49 & $32(57.1)$ & $17(30.4)$ & $0.004 *$ \\
\hline$>10,000$ & 63 & $24(42.9)$ & $39(69.6)$ & \\
\hline \multicolumn{5}{|l|}{ Education } \\
\hline Pre-university & 57 & 40 (71.4) & $17(30.4)$ & $<0.001^{*}$ \\
\hline University & 55 & 16 (28.6) & $39(69.6)$ & \\
\hline \multicolumn{5}{|l|}{ Staging } \\
\hline Early & 34 & 34 (60.7) & - & - \\
\hline Advanced & 22 & $22(39.3)$ & & \\
\hline \multicolumn{5}{|l|}{ Histology } \\
\hline Epithelial & 41 & $41 \quad(73.2)$ & - & - \\
\hline Non-epithelial & 15 & $15(26.8)$ & & \\
\hline \multicolumn{5}{|l|}{ State of treatment } \\
\hline \multicolumn{5}{|c|}{ Active disease with active treatment } \\
\hline & 21 & $21(37.5)$ & - & - \\
\hline \multicolumn{5}{|c|}{ Active disease with palliative treatment } \\
\hline & 4 & $4 \quad(7.1)$ & & \\
\hline \multicolumn{5}{|c|}{ Active disease with no treatment } \\
\hline & 1 & $1 \quad(1.8)$ & & \\
\hline Remission & 30 & $30(53.6)$ & & \\
\hline
\end{tabular}

Table 2. Comparison of Anxiety and Depression between Study Groups

\begin{tabular}{lccc}
\hline Outcomes & $\begin{array}{c}\text { Cancer } \\
\mathrm{N}(\%)\end{array}$ & $\begin{array}{c}\text { Non-cancer } \\
\mathrm{N}(\%)\end{array}$ & P-value \\
\hline Anxiety subscale (HADS-anxiety $\geq 11)$ & $4(7.1)$ & 1.00 \\
$4(7.1)$ & $1(1.8)$ & 1.00 \\
Depression-subscale (HADS-depression $\geq 11)$ & $2(3.6)$ & 0.09 \\
HADS Anxiety scores* $5.0(3.4 ; 0-15)$ & $6.1(3.3 ; 0-14)$ & 0.58 \\
HADS Depression scores* & $3.2(3.1 ; 0-14)$ & $3.5(2.7 ; 0-12)$ & 0.58 \\
&
\end{tabular}

alcohol consumption. However, participants in the noncancer group had significantly higher rate of medical comorbidity, higher proportion of those who had monthly salary of more than 10,000 baht, and higher proportion of university education. For participants in the cancer group, $60 \%$ were in early-stage, approximately $70 \%$ had epithelial cancer, and about half had their diseases in remission.

The Cronbach's alpha coefficients of internal consistency of the HADS questionnaires were 0.81 for 
Table 3. Association between Demographic/Clinical Factors and Anxiety in Participants with Ovarian Cancer

\begin{tabular}{|c|c|c|c|}
\hline Characteristics & $\mathrm{N}$ & Anxiety & P-value \\
\hline \multicolumn{4}{|l|}{ Age, years } \\
\hline$<50$ & 17 & $3(17.6)$ & \multirow[t]{2}{*}{0.08} \\
\hline$\geq 50$ & 39 & $1 \quad(2.6)$ & \\
\hline \multicolumn{4}{|l|}{ Marital status } \\
\hline Non-married & 23 & $2(8.7)$ & \multirow[t]{2}{*}{1.00} \\
\hline Married & 33 & $2(6.1)$ & \\
\hline \multicolumn{4}{|l|}{ Religion } \\
\hline Buddhist & 54 & $4 \quad(7.4)$ & \multirow[t]{2}{*}{1.00} \\
\hline Others & 2 & $\begin{array}{ll}0 & (0.0)\end{array}$ & \\
\hline \multicolumn{4}{|l|}{ Alcohol } \\
\hline Yes & 1 & $1(100.0)$ & \multirow[t]{2}{*}{0.07} \\
\hline No & 55 & $3 \quad(5.5)$ & \\
\hline \multicolumn{4}{|l|}{ Comorbidity } \\
\hline Yes & 14 & $1 \quad(7.1)$ & \multirow[t]{2}{*}{1.00} \\
\hline No & 42 & $3(7.1)$ & \\
\hline \multicolumn{4}{|l|}{ Salary } \\
\hline$\leq 10,000$ & 32 & $3 \quad(9.4)$ & \multirow[t]{2}{*}{0.63} \\
\hline$>10,000$ & 24 & $1 \quad(4.2)$ & \\
\hline \multicolumn{4}{|l|}{ Education } \\
\hline Pre-university & 40 & $4(10.0)$ & \multirow[t]{2}{*}{0.32} \\
\hline University & 16 & $\begin{array}{ll}0 & (0.0)\end{array}$ & \\
\hline \multicolumn{4}{|l|}{ Staging } \\
\hline Early & 34 & $4(11.8)$ & \multirow[t]{2}{*}{0.15} \\
\hline Advanced & 22 & $0 \quad(0.0)$ & \\
\hline \multicolumn{4}{|l|}{ Histology } \\
\hline Epithelial & 41 & $1 \quad(2.4)$ & \multirow[t]{2}{*}{0.06} \\
\hline Non-epithelial & 15 & $3(20.0)$ & \\
\hline \multicolumn{4}{|l|}{ Interval after diagnosis } \\
\hline$\leq 12$ months & 23 & $1 \quad(4.3)$ & \multirow[t]{2}{*}{0.63} \\
\hline$>12$ months & 32 & $3 \quad(9.4)$ & \\
\hline \multicolumn{4}{|l|}{ State of treatment } \\
\hline $\begin{array}{l}\text { Active disease with } \\
\text { active treatment }\end{array}$ & 21 & $\begin{array}{ll}0 & (0.0)\end{array}$ & \multirow[t]{4}{*}{0.29} \\
\hline $\begin{array}{l}\text { Active disease with } \\
\text { palliative treatment }\end{array}$ & 4 & $\begin{array}{ll}0 & (0.0)\end{array}$ & \\
\hline $\begin{array}{l}\text { Active disease with } \\
\text { no treatment }\end{array}$ & 1 & $\begin{array}{ll}0 & (0.0)\end{array}$ & \\
\hline Remission & 30 & $4(13.3)$ & \\
\hline
\end{tabular}

the anxiety subscale ( 0.81 in both groups) and 0.70 for the depression subscale $(0.75$ in the cancer group and 0.65 in the non-cancer group). Table 2 compares rate of anxiety and depression and HADS scores for anxiety and depression between the two study groups. The rates of anxiety and depression were comparable between the groups. In addition, the mean HADS-A and HADS-D scores were not significantly different between the groups. In multivariable analysis, no demographic or clinical factors significantly associated with anxiety were identified.

Table 3 demonstrates the association between demographic/clinical factors and anxiety in participants with ovarian cancer. No independent predicting factors for anxiety were identified in this group of patients. The mean HADS-A score in patients with early-stage disease (5.4 \pm 3.9$)$ was not significantly different from that of patients with advanced stage disease $(4.3 \pm 2.3)(\mathrm{P}=0.18)$. The mean HADS-A scores were not significantly different between patients with epithelial tumor $(4.7 \pm 2.7)$ and those with non-epithelial tumor $(5.9 \pm 4.7)$.

\section{Discussion}

Anxiety is one of the most common mental illness encountered in various healthcare settings (Wittchen et al., 2002). The prevalence of clinically significant anxiety symptoms (HADS-A score $\geq 11$ ) in this study was $7.1 \%$. The prevalence of anxiety and also of depression was not different between the cancer and non-cancer groups. In addition, the HADS-A and HADS-D scores were comparable between the groups. These findings are rather unexpected given the fact that approximately half of participants in the cancer group were still having active disease that required some forms of treatment. We were not able to identify any independent predicting factors for anxiety both for the cancer group and for the entire cohort. Of note, the prevalence of anxiety and depression in this study was lower than that in the previous studies that examined ovarian cancer patients with similar clinical characteristics. In the study of 246 patients with epithelial ovarian cancer (one-fourth were in early-stage and half were under active treatment), approximately $30 \%$ of the patients scored above the $75^{\text {th }}$ percentile of State Anxiety Subscale of the Spielberger State-Trait Anxiety Inventory and approximately $20 \%$ met the Center for Epidemiologic Studies-Depression (CES-D) clinical criteria for depression (Bodurka-Bevers et al., 2000). The incidence of anxiety and depression was $38 \%$ and $33 \%$, respectively in a prospective study of 63 ovarian cancer patients at the completion of chemotherapy. At three months follow-up, the rate of anxiety increased to $47 \%$ while the rate of depression decreased to $19 \%$. Poor perceived social support, increased intrusive thoughts and younger age were factors significantly associated with psychological morbidity (Hipkins et al., 2004).

Different from those studies, the Thai version of HADS was used in this study as a screening tool for anxiety and depression because of its reliability, validity, and simplicity. HADS has been confirmed to be a valid questionnaire with good performance in the screening of anxiety and depression in non-psychiatric setting. The cut-off score of $\geq 8$ is generally accepted as a threshold that provides optimal balance between sensitivity and specificity for both HADS-A and HADS-D as a case finder (Bjelland et al., 2002). However, for the Thai version, the cut-off point of $\geq 11$, which was used in this study, has been recommended. When tested in 60 in-patients with cancer using this cut-off point, the sensitivity and specificity of the anxiety subscale were $100 \%$ and $86 \%$, respectively while the sensitivity and specificity of the depression subscale were $85.7 \%$ and $91.3 \%$, respectively. In addition, good internal consistencies were demonstrated with the Cronbach's alpha coefficient of 0.86 for anxiety subscale and 0.83 for depression subscale (Nilchaikovit et al., 1996). In this study, the Cronbach's alpha coefficient could be considered good $(0.81)$ for the anxiety subscale and satisfactory $(0.70)$ for the depression subscale.

Recently, it was found that quality of life among Turkish women with ovarian cancer undergoing chemotherapy was moderately high, despite negative impact of the disease and treatment (Tuncay, 2014). Importantly, the author demonstrated that patients' problem-focused coping had 
Saranya Chittrakul et al

significant positive effect on both physical and spiritual well-being. The most frequently employed problemfocused coping in that setting included acceptance (an active attempt to learn to live with cancer and adapt to the situation), using emotional support, religion belief, and positive reframing. The benefit of acceptance and religious belief as major coping strategies in chronic illnesses was also suggested in other studies (Ramirez et al., 2012; Harris et al., 2013; Price et al., 2013). Feeling at peace and having a sense of meaning in life were found to be more important than having good and active physical condition among cancer patients receiving palliative care in a teaching hospital in Malaysia (Sharifa et al., 2014). These information regarding coping strategies might explain our findings, especially when cultural difference in coping is taken into account. However, information about coping strategy was not available in this study.

The majority of participants in the non-cancer control group in this study were women who came to the clinic for Pap smear screening, so they may not fully represent normal population. It is possible that anxiety level of cancer-conscious women who seek medical attention for cancer screening was higher than those who do not, especially while the screening result is pending. This factor might explain the lack of difference in anxiety symptoms.

Some study limitations should be noted. Although the two study groups were age-matched, there appeared to be significant imbalance in some demographic characteristics (comorbidity, salary, education) between the groups. These imbalanced characteristics could be considered confounders. The multivariable analysis was employed in an attempt to adjust for these confounding factors. In addition, the sample size was too small to determine possible difference in the prevalence of depression between the study groups and predicting factors for anxiety in ovarian cancer patients. Also, as mentioned earlier that there is high possibility of limited functional capacity, decreased sexual function, and compromised family and social role following the diagnosis of ovarian cancer, these variables were not evaluated in this study.

In conclusion, the prevalence of anxiety and depression in patients with ovarian cancer following primary surgical treatment was comparable to that of women who attended outpatient clinic for check-up in our setting. This might be explained by the patients' coping strategies. This issue of coping should be further explored in the future study.

\section{Acknowledgements}

Faculty of Medicine, Chiang Mai University and the National Research University Project under Thailand's Office of the Higher Education Commission provided funding support for this project.

\section{References}

Akkuzu G (2012). Quality of life of women undergoing chemotherapy for a gynaecological oncological disease in Turkey. Asian Pac J Cancer Prev, 13, 1277-80.

Akkuzu G, Ayhan A (2013). Sexual functions of Turkish women with gynecologic cancer during the chemotherapy process.
Asian Pac J Cancer Prev, 14, 3561-4.

Akkuzu G, Talas MS, Ortac F (2014). Functional status in Turkish women with gynecological cancer. Asian Pac J Cancer Prev, 15, 2045-9.

Bjelland I, Dahl AA, Haug TT, Neckelmann D (2002). The validity of the hospital anxiety and depression acale. An updated literature review. J Psychosom Res, 52, 69-77.

Bodurka-Bevers D, Basen-Engquist K, Carmack CL, et al (2000). Depression, anxiety, and quality of life in patients with epithelial ovarian cancer. Gynecol Oncol, 78, 302-8.

Cancer Incidence in Five Continents, Vol. X (electronic version) (2014). Eds Forman D, Bray F, Brewster DH, et al. IARC, Lyon. http://ci5 iarc.fr last accessed on November 4.

Chan JK, Urban R, Cheung MK, et al (2006). Ovarian cancer in younger vs older women: a population-based analysis. $\mathrm{Br} \mathrm{J}$ Cancer, 95, 1314-20.

Clevenger L, Schrepf A, Degeest K, et al (2013). Sleep disturbance, distress, and quality of life in ovarian cancer patients during the first year after diagnosis. Cancer, 119, 3234-41.

Fleming G, Seidman J, Lengyel E (2013). Epithelial ovarian cancer. In Principles and practice of gynecologic oncology $6^{\text {th }}$ ed., Eds Barakat RR, Berchuck A, Markman M, Randall M. Wolters Kluwer Health/Lippincott Williams \& Wilkins, Philadelphia pp 757-847.

Harris GM, Allen RS, Dunn L, Parmelee P (2013). "Trouble won't last always": religious coping and meaning in the stress process. Qual Health Res, 23, 773-81.

Hipkins J, Whitworth M, Tarrier N, Jayson G (2004). Social support, anxiety and depression after chemotherapy for ovarian cancer: a prospective study. Br J Health Psychol, 9, 569-81.

Murthy NS, Shalini S, Suman G, Pruthvish S, Mathew A (2009). Changing trends in incidence of ovarian cancer-the Indian scenario. Asian Pac J Cancer Prev, 10, 1025-30.

Nilchaikovit T, Lotrakul M, Phisansuthideth U (1996). Development of Thai version of Hos-pital anxiety and depression scale in cancer patients. J Psychiatr Assoc Thai, 41, 18-30.

Price MA, Bell ML, Sommeijer DW, et al (2013). Physical symptoms, coping styles and quality of life in recurrent ovarian cancer: a prospective population-based study over the last year of life. Gynecol Oncol, 130, 162-8.

Rai B, Bansal A, Patel FD, Sharma SC (2014). Radiotherapy for ovarian cancers-redefining the role. Asian Pac J Cancer Prev, 15, 4759-63.

Ramirez SP, Macedo DS, Sales PM, et al (2012). The relationship between religious coping, psychological distress and quality of life in hemodialysis patients. J Psychosom Res, 72, 12935.

Reid A, Ercolano E, Schwartz P, McCorkle R (2011). The management of anxiety and knowledge of serum CA-125 after an ovarian cancer diagnosis. Clin J Oncol Nurs, 15, 625-32.

Sharifa Ezat WP, Fuad I, Hayati Y, Zafar A, Wanda Kiyah GA (2014). Observational study on patient's satisfactions and quality of life (QoL) among cancer patients receiving treatment with palliative care intent in a tertiary hospital in Malaysia. Asian Pac J Cancer Prev, 15, 695-701.

Tuncay T (2014). Coping and quality of life in Turkish women living with ovarian cancer. Asian Pac J Cancer Prev, 15, 4005-12.

Wittchen HU, Kessler RC, Beesdo K, et al (2002). Generalized anxiety and depression in primary care: prevalence, recognition and management. J Clin Psychiatry, 63, 24-34.

Zigmond AS, Snaith RP (1983). The hospital anxiety and depression scale. Acta Psychiatr Scand, 67, 361-70. 